\title{
Thermal Denaturation and Aggregation Assays in Analytical Biochemistry
}

\section{Boris I. Kurganov*}

Bach Institute of Biochemistry, Russian Academy of Sciences, Moscow, Russia

In recent years, to screen the compounds revealing affinity to the proteins, the methods based on the registration of the change in thermal stability of proteins in the presence of the compounds being tested are widely used. In such experiments thermal denaturation is studied in the regime of heating of the protein solution at a constant rate. To control unfolding of the protein molecules, different physical methods are used, such as Differential Scanning Calorimetry (DSC) [1-9], intrinsic fluorescence [7,9,10-13], extrinsic fluorescence based on the measurements of the emission from extrinsic fluorescent dyes (8-anilino-1-napthalenesulfonic acid, 4,4'-bis(1-anilino-8naphthalenesulfonic acid), SYPRO Orange, Nile red) [14-27] and circular dichroism [10,28-30]. When denaturation of the protein is accompanied by irreversible aggregation of denatured protein molecules, the denaturation process can be followed by monitoring the increase in the light scattering of the protein solution [10,20,31-36] or the increase in apparent absorbance in the visible region $[7,11,30]$. The screening procedures using these physical methods can be automatized $[3,10,14,18,20,21,28,29,32,37-39]$ resulting in acceleration of searching the compounds which are of practical importance, for example, compounds that reveal affinity to protein target and act as potential pharmaceutical products.

The screening systems based on the registration of the increment of the light scattering intensity on heating of the protein solution at a constant rate are of special interest. It is evident that such test systems are applicable for searching the compounds specifically interacting with the proteins and for the rough estimate of the stability of the complexes protein-agent under test. Many investigators have restricted themselves to such an aspect of using of the screening systems. However one should take into account that the agents under study may affect not only the stage of protein denaturation but also the stage of aggregation of denatured molecules. In such cases the interpretation of the obtained results becomes complicated and the additional experiments should be performed to elucidate what stage of the general process of aggregation (stage denaturation or stage of aggregation) is affected by the agent under test. It is significant that, if for the screening systems, which are based on registration of excess heat capacity, fluorescence or ellipticity of the protein, aggregation is a factor complicating the interpretation of the results, for the screening systems based on registration of the light scattering intensity the investigator will have a chance of testing compounds that exert its action exclusively on the stage of protein aggregation. The case in point is an array of protein chaperones and low-molecular-weight chemical chaperones.

First of all, consider the principles of analysis of the dependences of the light scattering intensity on temperature for the screening systems in which the protein undergoes denaturation on heating at a constant rate. When studying aggregation of interleukin- $1 \beta$ and its mutant forms, Wetzel with coworkers $[40,41]$ used aggregation temperature $\left(T_{\mathrm{agg}}\right)$ to characterize the dependences of the light scattering intensity (I) on temperature ( $T$ ). Parameter $T_{\text {agg }}$ was defined as a length cut off on the abscissa axis by continuation of the linear part of the dependence of $I$ on $T$ (Figure 1A). The advantage of this approach is that only one parameter is used for characterization of the propensity of the protein to aggregation, namely parameter $T_{\text {agg }}$. There is a correlation between parameter $T_{\mathrm{agg}}$ characterizing thermal stability of sequence variants of interleukin- $1 \beta$ and the $\Delta \Delta G_{\mathrm{H}_{2} \mathrm{O}}^{0}$ value characterizing thermodynamic stability (the difference between the free energies of unfolding for mutant and for the wild type) for each sequence variant, as determined in reversible unfolding experiments in guanidine hydrochloride monitoring the fluorescence of the single tryptophan at position 120 .

The dependence of the light scattering intensity $(I)$ on temperature ( $T$ ) has a sigmoid shape. At rather high temperatures the light scattering intensity reaches a limiting value $\left(I_{\text {lim }}\right)$. To characterize thermostability of a protein, Senisterra and coworkers [31,33,35] used the temperature $\left(T_{\mathrm{agg}}\right)$ corresponding to the middle point of the transition, i.e., a temperature at which $I=I_{\lim } / 2$ (Figure 1B). Parameters $I_{\lim }$ and $T_{\text {agg }}$ are determined by fitting of the experimental dependence of $I$ on temperature with the following empiric equation, analogous to the Boltzmann equation:

$$
I=\frac{I_{\lim }}{1+\exp \left[\left(T_{\text {agg }}-T\right) / B\right]},
$$

where $B$ is a constant. According to Senisterra and coworkers parameter $T_{\text {agg }}$ may be considered as a measure of protein thermostability and the change in the $T_{\text {agg }}$ value in the presence of a ligand characterizes the effect of the latter on protein thermostability. To substantiate this conclusion, the authors used DSC, which is a source of direct information on the protein resistance to high-temperature exposure. The correlation between the $T_{\mathrm{agg}}$ value and the position of the maximum on the DSC profiles $\left(T_{\max }\right)$ was demonstrated [31,33].

Vedadi and coauthors [20] applied both fluorescence- and lightscattering-based approaches to measure the thermal stability of 221 recombinant proteins from humans and human parasites in the presence and absence of a range of chemicals. Purified proteins were subjected to gradually increasing temperature in both methods, and the temperature shift between the melting temperature $\left(T_{\mathrm{m}}\right.$ for fluorescence measurements or $T_{\text {agg }}$ for light-scattering measurements) in the presence and absence of a bound ligand was measured. The extent of the temperature shift is believed to be proportional to the affinity of the ligand for a given protein. The fluorescence and lightscattering approaches were applied to recombinant proteins in two experimental formats. In the first, the proteins were screened against a set of "generic" solution conditions designed to identify stabilizing conditions comprising salts, $\mathrm{pH}$, and simple additives, such as

*Corresponding author: Boris I. Kurganov, Bach Institute of Biochemistry, Russian Academy of Sciences, Moscow, Russia, Tel: +7(495)952-5641; Fax: +7(495)954-2732; E-mail: kurganov@inbi.ras.ru

Received November 06, 2013; Accepted November 07, 2013; Published November 11,2013

Citation: Kurganov BI (2013) Thermal Denaturation and Aggregation Assays in Analytical Biochemistry. Biochem Anal Biochem 2: e143. doi: 10.4172/21611009.1000e143

Copyright: (c) 2013 Kurganov BI. This is an open-access article distributed under the terms of the Creative Commons Attribution License, which permits unrestricted use, distribution, and reproduction in any medium, provided the original author and source are credited. 


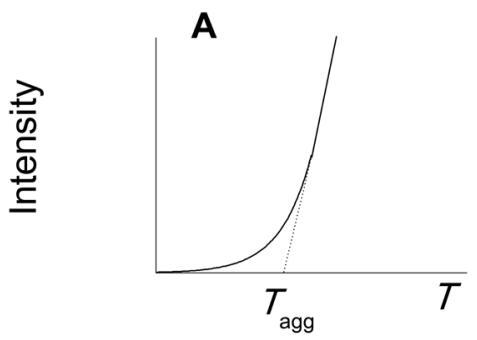

B

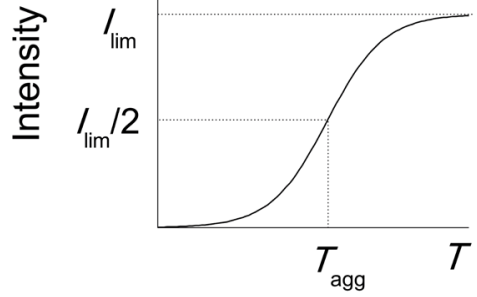

C

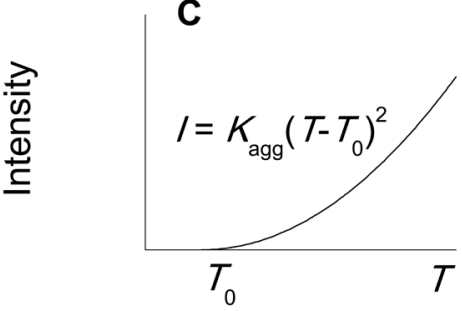

Figure 1: Analysis of the dependences of the light scattering intensity $(I)$ on temperature $(T)$ for thermal aggregation of proteins registered in the regime of heating of the protein solution at a constant rate. (A) To determine parameter $T$, the linear part of the dependence of $I$ on $T$ is extended until it intersects with the abscissa axis. (B) The application of equation (1) for the determination of parameter $T_{\text {agg }}$. (C) The application of equation (2) for the determination of parameter $T_{0}^{\text {agg }}$

nucleotides. In the second, which was targeted to proteins for which the activity was known, proteins were screened against a library of small molecules selected to be likely candidates for binding (e.g., protein kinases were screened against a library of known inhibitors from the patent literature). The aim of the work was to determine the frequency with which more optimal solution conditions and smallmolecule inhibitors could be identified by each method (fluorescence and light scattering) and determine the frequency with which these improved conditions were able to promote protein purification and/or crystallization. Of the 40 proteins for which both a $T_{\mathrm{m}}$ and a $T_{\mathrm{agg}}$ could be measured, the difference between $T_{\mathrm{agg}}$ and $T_{\mathrm{m}}$ varied depending on the protein; for 16 proteins $T_{\text {agg }}$ was lower than $T_{\mathrm{m}}$, whereas for 24 proteins $T_{\text {agg }}$ was higher than $T_{\mathrm{m}}$. It is possible that aggregation kinetics or a stabilization effect by the dye (SYPRO orange) account for these differences.

When studying thermal aggregation of human interleukin-1 receptor antagonist (IL-1ra), Raibekas [32] also used the midpoint aggregation curve-associated temperature $\left(T_{\mathrm{agg}}\right)$ to characterize the propensity of the protein to aggregation. The lower the $T_{\text {agg }}$ value, the higher is the propensity of IL-1ra to aggregation. Using this approach, the acceleration of aggregation of IL-1ra with increasing protein concentration was demonstrated.

It is evident that the accuracy of determining parameter $T_{\text {ag }}$ is connected with the reliability of the estimation of parameter $I_{\lim }$.
When trying to estimate parameter $I_{\lim }$, we should take into account that the "true" limiting level of the light scattering intensity may not be reached because of precipitation of the large-sized aggregates formed at high temperatures. Such a precipitation results in the decrease in the light scattering intensity, and the real experimental dependence of I on temperature looks like a curve passing through a maximum. The maximum value of the light scattering intensity may be lower than the $I_{\text {lim }}$ value calculated from Eq. (1). Besides, the correlation between the increment of the light scattering intensity and the degree of protein denaturation should be controlled not only by checking the correlation between parameters $T_{\text {agg }}$ and $T_{\mathrm{m}}$, but by strict analysis of the relationship between turbidimetric and calorimetric data, the latter supplying direct information on the degree of protein denaturation.

To avoid the uncertainty in the estimation of parameter $I_{\text {lim }}$, Eronina et al. [36] proposed to analyze the initial parts of the dependences of $I$ on temperature using the following empiric equation:

$$
I=K_{\text {agg }}\left(T-T_{0}\right)^{2} .\left(T>T_{0}\right)
$$

In this equation $T_{0}$ is the initial temperature of aggregation, i.e., the temperature at which the light scattering intensity begins to increase (Figure 1C), and $K_{\text {agg }}$ is a constant with the dimension of (counts $/ \mathrm{s}) \cdot\left({ }^{\circ} \mathrm{C}\right)^{-2}$. To demonstrate the applicability of this equation, the data on thermal aggregation of glycogen phosphorylase $b$ (EC 2.4.1.1), glyceraldehyde-3-phosphate dehydrogenase (EC 1.2.1.12) and creatine kinase (EC 2.7.3.2) from rabbit skeletal muscles and bovine liver glutamate dehydrogenase (EC 1.4.1.3) were used [36]. The measurements of the hydrodynamic radius of the protein aggregates showed that the initial temperature of aggregation $\left(T_{0}\right)$ indicates the moment of origination of the start aggregates. The hydrodynamic radius of the start aggregates $\left(R_{\mathrm{h}, 0}\right)$ is several tens of nanometers. The analysis of the data obtained by Golub et al. [42] shows that analogous situation takes place for thermal aggregation of aminotransferase (EC 2.6.1.1) from pig heart mitochondria $\left(T_{0}=54.6 \pm 0.5^{\circ} \mathrm{C}\right.$ and $R_{\mathrm{h} .0}$ $=60 \pm 1 \mathrm{~nm}$ ). As demonstrated in [36], the $T_{0}$ value decreases with increasing the protein concentration whereas parameter $K_{\mathrm{agg}}$, which can be considered as a measure of the aggregation rate, increases as the protein concentration increases.

Aggregation systems under discussion may be used for testing the compounds affecting protein stability as a result of direct binding to the native protein molecule (for example, substrates and modifiers of the enzymes). Besides, test systems based on thermal aggregation of model proteins in the regime of heating at a constant rate allow the antiaggregation properties of the compounds possessing chaperone-like activity (for example, small heat shock proteins) to be characterized [43-49]. Strictly speaking, if we want to select agents affecting exclusively the stage of denaturation, we should demonstrate that these agents have no effect on the stage of aggregation. To solve this problem, the investigator should have at his disposal the screening systems which allow the effect of the agents on the stage of protein aggregation to be tested. In test systems of such a type the preliminary denatured protein should be used. For example, test systems based on aggregation of ultraviolet-irradiated proteins are suitable to characterize the direct action of the agents under study on the stage of aggregation [50-53]. DSC was used in these experiments to prove protein denaturation under UV light.

In conclusion, it should be emphasized that the approaches discussed here have the potential to become an effective screening tool for ligands and buffer excipients influencing protein stability 
Citation: Kurganov BI (2013) Thermal Denaturation and Aggregation Assays in Analytical Biochemistry. Biochem Anal Biochem 2: e143. doi: 10.4172/2161-1009.1000e143

Page 3 of 4

and aggregation processes. This study was funded by the Russian Foundation for Basic Research (grant 11-04-00932-a) and the Program "Molecular and Cell Biology" of the Presidium of the Russian Academy of Sciences.

\section{References}

1. Brandts JF, Lin LN (1990) Study of strong to ultratight protein interactions using differential scanning calorimetry. Biochemistry 29: 6927-6940.

2. Chan HK, Au-Yeung KL, Gonda I (1996) Effects of additives on heat denaturation of rhDNase in solutions. Pharm Res 13: 756-761.

3. Plotnikov V, Rochalski A, Brandts M, Brandts JF, Williston S, et al. (2002) An autosampling differential scanning calorimeter instrument for studying molecular interactions. Assay Drug Dev Technol 1: 83-90.

4. Weber PC, Salemme FR (2003) Applications of calorimetric methods to drug discovery and the study of protein interactions. Curr Opin Struct Biol 13: 115121.

5. Levitsky DI (2004) Structural and functional studies of muscle proteins by using differential scanning calorimetry: The Nature of Biological Systems as Revealed by Thermal Methods. Kluwer Academic Publishers, New York 127-158.

6. Goldberg DS, Bishop SM, Shah AU, Sathish HA (2011) Formulation development of therapeutic monoclonal antibodies using high-throughput fluorescence and static light scattering techniques: Role of conformational and colloidal stability. J Pharm Sci 100: 1306-1315.

7. Cheng W, Joshi SB, He F, Brems DN, He B et al. (2012) Comparison of highthroughput biophysical methods to identify stabilizing excipients for a mode IgG2 monoclonal antibody: conformational stability and kinetic aggregation measurements. J Pharm Sci 101: 1701-1720.

8. Shi S, Liu J, Joshi SB, Krasnoperov V, Gill P, et al. (2012) Biophysica characterization and stabilization of the recombinant albumin fusion protein sEphB4-HSA. J Pharm Sci 101: 1969-1984.

9. Thakkar SV, Joshi SB, Jones ME, Sathish HA, Bishop SM, et al. (2012) Excipients differentially influence the conformational stability and pretransition dynamics of two IgG1 monoclonal antibodies. J Pharm Sci 101: 3062-3077.

10. Samra HS, He F, Bhambhani A, Pipkin JD, Zimmerer R, et al. (2010) The effects of substituted cyclodextrins on the colloidal and conformational stability of selected proteins. J Pharm Sci 99: 2800-2818.

11. Bhambhani A, Kissmann JM, Joshi SB, Volkin DB, Kashi RS et al. (2012) Formulation design and high-throughput excipient selection based on structural integrity and conformational stability of dilute and highly concentrated IgG1 monoclonal antibody solutions. J Pharm Sci 101: 1120-1135.

12. Thakkar SV, Kim JH, Samra HS, Sathish HA, Bishop SM, et al. (2012) Loca dynamics and their alteration by excipients modulate the global conformational stability of an IgG1 monoclonal antibody. J Pharm Sci 101: 4444-4457.

13. Hu L, Joshi SB, Liyanage MR, Pansalawatta M, Alderson MR, et al. (2013) Physical characterization and formulation development of a recombinan pneumolysoid protein-based pneumococcal vaccine. J Pharm Sci 102: 387400

14. Pantoliano MW, Petrella EC, Kwasnoski JD, Lobanov VS, Myslik J, et al. (2001) High-density miniaturized thermal shift assays as a general strategy for drug discovery. J Biomol Screen 6: 429-440.

15. Lo MC, Aulabaugh A, Jin G, Cowling R, Bard J, et al. (2004) Evaluation of fluorescence-based thermal shift assays for hit identification in drug discovery. Anal Biochem 332: 153-159.

16. Carver TE, Bordeau B, Cummings MD, Petrella EC, Pucci MJ, et al. (2005) Decrypting the biochemical function of an essential gene from Streptococcus pneumoniae using ThermoFluor technology. J Biol Chem 280: 11704-11712.

17. Matulis D, Kranz JK, Salemme FR, Todd MJ (2005) Thermodynamic stability of carbonic anhydrase: measurements of binding affinity and stoichiometry using ThermoFluor. Biochemistry 44: 5258-5266.

18. Cummings MD, Farnum MA, Nelen MI (2006) Universal screening methods and applications of ThermoFluor. J Biomol Screen 11: 854-863.

19. Ericsson UB, Hallberg BM, Detitta GT, Dekker N, Nordlund P (2006) Thermofluor-based high-throughput stability optimization of proteins for structural studies. Anal Biochem 357: 289-298.
20. Vedadi M, Niesen FH, Allali-Hassani A, Fedorov OY, Finerty PJ Jr, et al. (2006) Chemical screening methods to identify ligands that promote protein stability, protein crystallization, and structure determination. Proc Natl Acad Sci U S A 103: $15835-15840$

21. Niesen $\mathrm{FH}$, Berglund $\mathrm{H}$, Vedadi $\mathrm{M}$ (2007) The use of differential scanning fluorimetry to detect ligand interactions that promote protein stability. Nat Protoc 2: 2212-2221.

22. Senisterra GA, Soo Hong B, Park HW, Vedadi M (2008) Application of highthroughput isothermal denaturation to assess protein stability and screen for ligands. J Biomol Screen 13: 337-342.

23. Alexandrov AI, Mileni M, Chien EY, Hanson MA, Stevens RC (2008) Microscale fluorescent thermal stability assay for membrane proteins. Structure 16: $351-$ 359 .

24. Cimmperman P, Baranauskiene L, JachimoviciÅ«te S, Jachno J, Torresan J, et al. (2008) A quantitative model of thermal stabilization and destabilization of proteins by ligands. Biophys J 95: 3222-3231.

25. Layton CJ, Hellinga HW (2010) Thermodynamic analysis of ligand-induced changes in protein thermal unfolding applied to high-throughput determination of ligand affinities with extrinsic fluorescent dyes. Biochemistry 49: 1083110841.

26. He F, Woods CE, Trilisky E, Bower KM, Litowski JR et al. (2010) Screening of monoclonal antibody formulations based on high-throughput thermostability and viscosity measurements: Design of experiment and statistical analysis. $J$ Pharm Sci.

27. Senisterra G, Chau I, Vedadi M (2012) Thermal denaturation assays in chemical biology. Assay Drug Dev Technol 10: 128-136.

28. Patel R, Lebrun LA, Wang S, Howett LJ, Thompson PA et al. (2008) ATLAS - a high-throughput affinity-based screening technology for soluble proteins: technology application using p38 MAP kinase. Assay Drug Dev Technol 6: 5568.

29. Thompson PA, Wang S, Howett LJ, Wang MM, Patel R, et al. (2008) Identification of ligand binding by protein stabilization: comparison of ATLAS with biophysical and enzymatic methods. Assay Drug Dev Technol 6: 69-81.

30. Cirkovas A, Sereikaite J (2011) Different effects of (L)-arginine on the heatinduced unfolding and aggregation of proteins. Biologicals 39: 181-188.

31. Senisterra GA, Markin E, Yamazaki K, Hui R, Vedadi M, et al. (2006) Screening for ligands using a generic and high-throughput light-scattering-based assay. $J$ Biomol Screen 11: 940-948.

32. Raibekas AA (2008) Estimation of protein aggregation propensity with a melting point apparatus. Anal Biochem 380: 331-332.

33. Senisterra GA, Finerty PJ Jr (2009) High throughput methods of assessing protein stability and aggregation. Mol Biosyst 5: 217-223.

34. Cai S, He F, Samra HS, de la Maza LM, Bottazzi ME, et al. (2009) Biophysica and stabilization studies of the Chlamydia trachomatis mouse pneumonitis major outer membrane protein. Mol Pharm 6: 1553-1561.

35. Senisterra GA, Ghanei H, Khutoreskaya G, Dobrovetsky E, Edwards AM, et al (2010) Assessing the stability of membrane proteins to detect ligand binding using differential static light scattering. J Biomol Screen 15: 314-320.

36. Eronina T, Borzova V, Maloletkina O, Kleymenov S, Asryants R, et al. (2011) A protein aggregation based test for screening of the agents affecting thermostability of proteins. PLoS One 6: e22154.

37. Kamerzell TJ, Esfandiary R, Joshi SB, Middaugh CR, Volkin DB (2011) Proteinexcipient interactions: mechanisms and biophysical characterization applied to protein formulation development. Adv Drug Deliv Rev 63: 1118-1159.

38. Maddux NR, Rosen IT, Hu L, Olsen CM, Volkin DB, et al. (2012) An improved methodology for multidimensional high-throughput preformulation characterization of protein conformational stability. J Pharm Sci 101: 20172024

39. Chaudhuri R, Cheng Y, Middaugh CR, Volkin DB (2013) High-throughput biophysical analysis of protein therapeutics to examine interrelationships between aggregate formation and conformational stability. AAPS J.

40. Chrunyk BA, Wetzel R (1993) Breakdown in the relationship between therma and thermodynamic stability in an interleukin-1 beta point mutant modified in a surface loop. Protein Eng 6: 733-738. 
Citation: Kurganov BI (2013) Thermal Denaturation and Aggregation Assays in Analytical Biochemistry. Biochem Anal Biochem 2: e143. doi: 10.4172/2161-1009.1000e143

41. Chrunyk BA, Evans J, Lillquist J, Young P, Wetzel R (1993) Inclusion body formation and protein stability in sequence variants of interleukin-1 beta. J Biol Chem 268: 18053-18061.

42. Golub NV, Markossian KA, Kasilovich NV, Sholukh MV, Orlov VN et al. (2008) Thermal inactivation, denaturation and aggregation of mitochondrial aspartate aminotransferase. Biophys Chem 135: 125-131.

43. Pivovarova AV, Mikhailova VV, Chernik IS, Chebotareva NA, Levitsky DI et al (2005) Effects of small heat shock proteins on the thermal denaturation and aggregation of F-actin. Biochem Biophys Res Commun 331: 1548-1553.

44. Meremyanin AV, Eronina TB, Chebotareva NA, Kleimenov SY, Yudin IK, et al. (2007) Effect of alpha-crystallin on thermal aggregation of glycogen phosphorylase b from rabbit skeletal muscle. Biochemistry (Mosc) 72: 518-528.

45. Khanova HA, Markossian KA, Kleimenov SY, Levitsky DI, Chebotareva NA, et al. (2007) Effect of alpha-crystallin on thermal denaturation and aggregation of rabbit muscle glyceraldehyde-3-phosphate dehydrogenase. Biophys Chem 125: 521-531.

46. Pivovarova AV, Chebotareva NA, Chernik IS, Gusev NB, Levitsky DI (2007) Small heat shock protein Hsp27 prevents heat-induced aggregation of F-actin by forming soluble complexes with denatured actin. FEBS J 274: 5937-5948.

47. Levitsky DI, Pivovarova AV, Mikhailova VV, Nikolaeva OP (2008) Thermal unfolding and aggregation of actin. FEBS J 275: 4280-4295.
48. Kazakov AS, Markov DI, Gusev NB, Levitsky DI (2009) Thermally induced structural changes of intrinsically disordered small heat shock protein Hsp22. Biophys Chem 145: 79-85.

49. Sluchanko NN, Artemova NV, Sudnitsyna MV, Safenkova IV, Antson AA, et al. (2012) Monomeric 14-3-3 has a chaperone-like activity and is stabilized by phosphorylated HspB6. Biochemistry 51: 6127-6138.

50. Muranov KO, Maloletkina OI, Poliansky NB, Markossian KA, Kleymenov SY, et al. (2011) Mechanism of aggregation of UV-irradiated $\beta(L)$-crystallin. Exp Eye Res 92: 76-86.

51. Roman SG, Chebotareva NA, Eronina TB, Kleymenov SY, Makeeva VF, et al. (2011) Does the crowded cell-like environment reduce the chaperone-like activity of $\alpha$-crystallin? Biochemistry 50: 10607-10623.

52. Maloletkina OI, Markossian KA, Chebotareva NA, Asryants RA, Kleymenov SY, et al. (2012) Kinetics of aggregation of UV-irradiated glyceraldehyde3-phosphate dehydrogenase from rabbit skeletal muscle. Effect of agents possessing chaperone-like activity. Biophys Chem 163-164: 11-20.

53. Roman SG, Chebotareva NA, Kurganov BI (2012) Concentration dependence of chaperone-like activities of $\alpha$-crystallin, $\alpha \mathrm{B}$-crystallin and proline. Int $\mathrm{J}$ Biol Macromol 50: 1341-1345 